\title{
Analyzing UK's Biogas from Waste Scheme Through the Lens of Circular Economy
}

\author{
Abhijeet Acharya ${ }^{1}$ \\ ${ }^{1}$ College of Management and Technology, Walden University, Minnesota, USA \\ Correspondence: Abhijeet Acharya, College of Management and Technology, Walden University, Minnesota, USA. \\ E-mail: abhijeet.acharya@waldenu.edu
}

Received: September 18, 2020

Accepted: October 15, $2020 \quad$ Online Published: October 18, 2020

doi:10.5539/jsd.v13n6p73

URL: https://doi.org/10.5539/jsd.v13n6p73

\begin{abstract}
The biogas from waste has emerged as a realistic and reliable renewable energy proposition and can deliver socialeconomic benefits when integrated with local communities. In the last decade, the biogas sector in European countries has seen unprecedented growth due to favorable policy supports and perceived social-economic benefits. Among different biogas producing schemes, waste to biogas using anaerobic digestion is considered most environment friendly due to minimum carbon leakage and positive waste resource recycling impact. Many countries, including the UK, envision creating a circular economy utilizing Biogas from Waste (BfW) recycling potential. This paper aims to analyze the state of the UK's BfW scheme through the lens of circular economy and discern areas that need attention to usher BfW potential in supporting a circular economy. The paper also discussed key challenges and barriers to create a local circular economy using the BfW scheme. Based on the analysis, it is observed that the BfW scheme in the UK is currently impeded due to lack cross-sectoral policy coherence, and far from contributing to a circular economy. Additionally, the UK's waste to energy concept is concentrated around incinerator-based systems without much attention on improving resource efficiency and waste recycling. This paper makes three recommendations to improve prospects of the BfW scheme in the UK (1) decentralized approach in the BfW scheme development, (2) considering bio-waste and digestate as value streams, and (3) creating a policy cohesiveness across multiple departments.
\end{abstract}

Keywords: biogas, anaerobic digestion, circular economy, waste recycling, resource efficiency

\section{Introduction}

\subsection{Background}

In the last decade, biogas has emerged as a strong alternative to fossil-based natural gas. European countries provide policy support to integrate biogas into the energy mix with the objectives a) reduce greenhouse gas emission, b) create social-economic benefits for communities, and c) reduce dependency on natural gas imports. In the year 2017, more than 17,700 biogas plants were operational in Europe; Germany led the biogas production with over 10,000 plants, Italy, in second place with over 1,600 plants, followed by France, Switzerland and the UK with over 600 plants (EBA, 2019). Biogas, generated from multiple feedstocks solid waste, liquid sewage, landfill waste, and energy crops, are available in various forms of energy such as biomethane, biofuel, and bioethanol. Due to sustainability issues associated with landfill waste and energy crops, many countries use liquid sewage and solid waste as the primary feedstock for biogas production (Fagerström et al., 2018). The difficulty in full recovery of produced biogas and methane leakage issues made landfill-based production restricted in many countries (Capodaglio, Callegari, \& Lopez, 2016). Anaerobic Digestion (AD) has emerged as an economically viable option since these plants decrease the negative environmental impacts by preventing methane leakage and producing digestate as byproducts used as fertilizer to provide additional income to farmers (Lauer et al., 2018). Biogas producing $\mathrm{AD}$ plants can digest different organic feedstocks and produce a range of byproducts; therefore, they can play a significant role in the circular economy (Fagerström et al., 2018). The circular economy model guided by the system thinking approach creates an alignment between technological and social-economic benefits to minimize waste and promote recycling of materials, thereby reducing environmental impact and contributing to sustainability development (Ellen McArthur foundation, 2015). AD process has emerged as the preferred scheme for waste to energy route; the European Union (EU) has integrated the AD process into waste and circular economy policies (Kampman et al., 2017). The BfW facilities based on the AD process are seen as a closed recycle system 
where value is created from waste materials; the process also meets sustainability criteria and has the potential to create financial, social, and environmental values for the local community (Fagerström et al., 2018).

According to DEFRA (2018), UK's circular economy strategy prioritizes resource efficiency and bio-waste recycling using a sustainable and environmentally friendly waste management scheme that pivots on the $\mathrm{AD}$ process. The UK's energy policy is committed to produced biogas by reducing greenhouse emissions and managing the risks of food security and biodiversity (Adams, Mezzullo, \& McManus, 2015). BfW sector growth in the UK has been supported by Feed-in-Tariffs (FIT) and Renewable Heat Incentives (RHI); the number of AD plants using food or farm waste has increased from 63 in 2011 to around 400 in 2017. Also, energy recovered has increased from $713 \mathrm{GWh}$ in 2013 to 2,470 GWh in 2017 (DEFRA, 2018). In contrast to the UK's vision of creating a circular economy based on BfW using AD plants, the UK government has cut financial supports and incentives in recent years. FIT and RHI's reduction is not favorable to BfW schemes; future growth will further slow after complete FIT withdrawal in 2019 (IEA Bioenergy, 2017). Additionally, the UK's waste processing infrastructure is predominantly based on a linear model with limited investments to develop infrastructure for supporting the circular economy. Between 2012-2017, the government-owned green investment bank in the UK made significant investments in incinerator-based energy generation with no major funding to improve recycling infrastructure. The government investments contributed to capacity expansion of $2.7 \mathrm{mtpa}$ for incinerator-based energy generations against $0.29 \mathrm{mtpa}$ capacity for AD plants (Peake \& Brandmayr, 2019). Another challenge in the effective utilization of BfW recycle capability in creating a circular economy is the centralized social-technical structure of the UK's energy regime. Levidow and Raman (2020) proposed the eco-localization concept to promote decentralized and distributed BfW systems to increase bioenergy's social-economic benefits by involving local communities and municipalities in resource planning.

\subsection{Aim of the Paper}

This paper aims to analyze the state of the BfW scheme in the UK through the lens of circular economy and discern areas that need attention to usher BfW potential in supporting a circular economy. The paper also makes recommendations to improve the recycling potential of the BfW scheme. The positive recycling impact for local communities alongside delivering social-economic benefits and addressing sustainability concerns makes BfW scheme a perfect business case from the circular economy perspective. In section 1, I discussed the potential benefits of BfW based on the AD plants and provided a brief background of the BfW scheme in the UK. I detailed the methodology used in section 2. Section 3 discusses the circular economy concept and various elements involved in it. The UK's BfW sector status, support policies, the importance of the decentralized initiative, and local actors' role are discussed in section 4. I discussed critical success factors in section 5 related to UK's BfW scheme by comparing the UK's business practices with other European nations who successfully improved resource recycling and achieved significant growth in the BfW sector. I also made recommendations to enhance BfW recycling potential to support the localized circular economy in section 5. Section 6 concludes this paper by highlighting areas that need immediate attention to support a CE model and makes recommendations for the UK's BfW sector growth.

\section{Materials and Method}

I conducted a literature review on papers related to the bio-waste recycling-based $\mathrm{CE}$ model published within the last five years. The substantive literature review helped me develop a conceptual understanding of the bio-waste recycling-based CE model. To get an insight into the UK's BfW scheme, I conducted a literature review on peerreviewed papers, publications, and reports from government bodies on the UK's waste management sector. In the discussion section, I analyze the UK's BfW scheme by contrasting with strategies of other European counties that have successfully improved bio-waste collection and recycling. I also compared bio-waste collection and recycling strategies within the UK member states intending to identify best practices being implemented in the UK. Based on the analysis, I identified key areas in the UK's BfW scheme that requires immediate attention. I also made recommendations to improve resource efficiency to usher the BfW scheme's potential in supporting the CE model.

\section{Circular Economy Concept}

Organizations aimed at meeting higher product demand and making profits used a linear economic model based on taking, producing, consuming, and disposing of the valuable resource without focusing on re-usability or recycling disposed waste (Malinauskaite et al., 2017). The beginning of the 21st century is marked with concerns related to sustainability, greenhouse emission, and resource constraints when organizations focus on resource efficiency and recycling waste. In contrast to the linear economic model, the Circular Economy (CE) model is based on restorative and regenerative design and aims to keep products, components, and materials at their highest utility and value in the entire lifecycle (Ellen McArthur foundation, 2015; Fagerström et al., 2018). Murray et al. 
(2017) conceptualized CE as an economic model wherein planning, resourcing, procurement, production, and reprocessing are designed and managed, as both process and output, to maximize ecosystem functioning and human well-being. Kirchherr, Reike, and Hekkert (2017) gathered 114 circular economy definitions having multiple dimensions and conceptualized the $\mathrm{CE}$ through an iterative process as below,

"CE an economic system that replaces the 'end-of-life' concept with reducing, alternatively reusing, recycling, and recovering materials in production/distribution and consumption processes. It operates at the micro-level (products, companies, consumers), meso-level (ecoindustrial parks), and macro-level (city, region, nation and beyond), with the aim to accomplish sustainable development, thus simultaneously creating environmental quality, economic prosperity, and social equity, to the benefit of current and future generations. It is enabled by novel business models and responsible consumers."

Scholars have a consensus about a close relationship between the CE model and sustainable development. SuarezEiroa et al. (2019) stated that the CE model could be placed at the intersection of economy, society, and environmental dimensions. In the $\mathrm{CE}$ model value of the product, material and resources are maintained for the longest possible time, focusing on minimizing waste and increasing resource utilization; the CE concept allows turning waste into a valuable resource for local communities (Malinauskaite et al., 2017). EU's CE policy proposed in 2015 is based on 'close the loop' of product lifecycles, emphasizing recycling and reuse and bringing socialeconomic benefits for the communities (Kampman et al., 2017). EU's CE model is pivoted around waste management, covering the full life cycle from production and consumption to disposal and adds marketable value to wastes as raw materials (Rada et al., 2018). The biogas from waste streams that cannot be reused is the wellaligned waste management policy of the $\mathrm{EU}$; the $\mathrm{AD}$ process used for the $\mathrm{BfW}$ scheme contributes to the objectives and targets of the EU's waste-based circular economy policies (Kampman et al., 2017). The research community working in the biogas sector agrees that BfW generation is a perfect business case for the CE model. The BfW from the $\mathrm{CE}$ model perspective creates environment values and adds social and economic values for local communities (Fagerström et al., 2018). Biogas production from the BfW scheme is adherent to CE principles; this includes aspects of the environment, economic, and social sectors (Rada et al., 2018). Having discussed the CE concept, I aim to discuss key elements in the CE model.

In the $\mathrm{CE}$ model, a system approach allows keeping an account for material transfer within the system and any leakage or un-accounted material to externalities. A CE model comprises small businesses, people, and subsystems. CE model is a complex system where such elements are connected in a causal relationship; therefore, a system thinking approach can recognize such relations and the extent of impact (Ellen McArthur foundation, 2015). The system thinking approach permits us to identify ecosystem actors and their essential transactions for the CE model. After the business unit is conceptualized as a CE system, it is also essential that such a system is isolated from externalities. The closed system approach is a key element in implementing the CE model, where the recycle stage is connected to resource acquisition and finished product (Suarez-Eiroa et al., 2019). A closed system improves the re-usability of waste material and increases the recycling process's success rate (Rada et al., 2018). A closed-loop system approach creates a value chain, improving recycling efficiency and the CE model (Fagerström et al., 2018).

Ensuring consistency and quality of feedstock resource is a critical element of the CE model. AD operators must know the feedstock composition. A clear distinction between renewable and non-renewable material should be assessed while designing a system; the focus should be to reduce consumption of non-renewable resources and increase the extraction of renewable resources (Suarez-Eiroa et al., 2019). Resource efficiency is the critical success factor of the CE model, where the focus is to reduce the consumption of non-renewable resources and increase the circulation of renewable material. However, it is impossible to achieve a perfect CE model with 100\% resource efficiency (Van Ewijk, 2018). Lindvist et al. (2019) recommended resource efficiency assessment in the BfW scheme should include economy, energy, and environmental perspective; based on the outcome, a decision can be made to select the most appropriate biogas generation process. Waste material may contain unwanted substances such as pathogens, antibiotics, pharma residues, plastics, or heavy metals; in a CE model, where the same material is recirculated many times, the possibility of resource degradation and contamination in a closedloop needs to be assessed (Fagerström et al., 2018). Therefore, a resource efficiency assessment improves the sustainability of the supply chain and maximizes social-economic benefits.

Local partnership and collaboration between the actors are essential aspects of the CE model. Social actors and their networking activities take center stage in the CE model; individual actors must discharge their responsibility ethically throughout the networks (Murray et al., 2017). Due to interconnected processes and interdependency between social actors, CE models require a collaborative work culture (Suarez-Eiroa et al., 2019). Local authorities 
and municipalities can play an active role in regional planning, identifying potential biogas sources, and explore new opportunities. Local NGOs and social actors can initiate campaigns about biogas-based CE models' effectiveness with their environmental and social-economic benefits (Kampman et al., 2017). Murray et al. (2017) highlighted that NGOs and social actors support CE models in partnership with public and private enterprises in the Netherlands and other EU countries. Usually, biogas-based CE models involve multiple stakeholders and different government agencies with various policies and priorities. Local waste management authorities engaged in developing a BfW system must comply with diverse waste management policies, energy, agriculture, and environment (Malinauskaite et al., 2017). Yazan et al. (2018) showed a regional network of actors and intermediaries such as feedstock suppliers and buyers, logistics players, or farmer coalitions have shared economic benefits in the CE model. Therefore, it is recommended that multiple actor-networks are modelled in the biogasbased CE viability study.

Under the CE model, the BfW scheme should be supported as a viable business case rather than just a means of waste management. Linking biogas production to the natural gas grid or further distribution and considering digestate as a valuable byproduct can improve business case viability (Kampman et al., 2017). When the CE model is viewed as a business case, it permits society, technology, and knowledge to come together to create new values through collaboration, knowledge exchange, and improved resource efficiency (Ellen McArthur foundation, 2015). Bio-waste presents immense opportunity to create economic values in the CE model; a sound business case can permit the commercialization of the product, which attracts other industry actors and private investors to get involved in the project (Malinauskaite et al., 2017). Kirchherr et al. (2017) argued a viable business model is the main driving force and key enabler behind the $\mathrm{CE}$ concept and suggested that adding consumer-side demands and services can further contribute to CE's success. A circular model is generally considered cross-sectoral due to the involvement of multiple actors from different business sectors; therefore, a collaborative business model is imperative for the $\mathrm{CE}$ system. In BfW based CE model, where multiple agencies and intermediaries are involved, a collaborative business model provides a platform for information sharing, joint collection systems, aligned incentives to create cohesion across sectors or between businesses and policymakers (Ellen McArthur foundation, 2015). Building on literature review, I observed that the CE is an evolving concept; however, it provides a robust framework for reviewing the BfW scheme's development. The four essential elements of the CE model observed in the literature review are 1) a system approach, 2) resource efficiency and closed-loop approach, 3) local collaboration between actors, and 4) viable business case.

\section{Waste to Bigas Activities in UK}

\subsection{BfW Evolution}

To mitigate the environmental impact from the release of trapped methane gas in landfilled biodegradable organic waste, the EU countries, including the UK, proposed a landfill directive (1999/31/EC). The landfill directive requires EU countries to achieve a 65\% reduction in biodegradable waste disposal by 2020 relative to 1995 levels (Zglobisz et al., 2010). Throughout the EU, the waste and landfill directives encouraged member states to implement collection and processing systems for the organic waste stream (Kampman et al., 2017). Like other EU countries, the UK implemented Landfill Allowance Trading Scheme (LATS), which allowed local authorities to divert biodegradable waste from landfills and use it as a resource for renewable energy generation (Zglobisz et al., 2010). In 2010, the UK government committed to working towards a 'zero waste' economy and proposed to generate renewable energy from biodegradable waste using the $\mathrm{AD}$ process (DEFRA, 2011). AD can be important means of dealing with organic waste and preventing methane emissions associated with its disposal to the landfill; The technology also offers other benefits, such as recovering energy, producing valuable biofertilizers, and using the nutrients (DEFRA, 2011). Landfill tax and gate fee charges provide a viable revenue stream to waste management (Zglobisz et al., 2010).

UK's renewable energy act 2008 provided feed-in-tariffs (FIT) support as a guaranteed price for a fixed period to small-scale biogas-based electricity generators using AD facilities (Zglobisz et al., 2010; IEA Bioenergy, 2020). Additionally, Renewable Heat Incentive (RHI) was introduced in 2014 to provide a fixed income (pence/kWh) to generators/users of renewable heat and also benefited renewable biogas and biomethane producers (IEA Bioenergy, 2020). The renewable obligation act 2009 required energy supplies to source minimum energy from renewable sources and issued one Renewable Obligation Certificate (ROC) for each MWh of energy. Especially, waste to energy technologies have significantly benefited from this act, BfW based on the AD process, was eligible to receive two ROCs for each $1 \mathrm{MWh}$ of energy produced (Zglobisz et al., 2010).

In 2008, the UK transport department aimed to reduce greenhouse emissions from road transport and proposed a Renewable Transport Fuel Obligation (RTFO) scheme to encourage renewable fuel mix supply. Under the RTFO, 
renewable fuels must meet specified sustainability criteria to receive Renewable Transport Fuel Certificates. Biomethane, a byproduct of biogas produced from biodegradable waste, would receive 3.8 RTFCs per kilogram compared to 1.9 RTFCs for biomethane generated from other sources (Department of Transport, 2019).

Like other EU countries, UK envisions moving away from the linear economic model to the CE model by using resources efficiently and prolonging the material lifecycle used in the supply chain. A circular economy in the UK aims to keep resources utilization as long as possible to extract maximum value from waste; the UK's CE strategy targets to achieve a 50\% recycling rate for household waste by 2020 and a $65 \%$ recycling rate for municipal solid waste by 2035 (DEFRA, 2018). Due to higher recycling efficiency and being environment friendly, the AD process is considered a superior solution to waste incineration. In general, incinerators have lower energy recovery of 15 to $25 \%$, and the ash as a byproduct requires further treatment (DEFRA, 2014). The move towards a low carbon and resource-efficient economy centered around the $\mathrm{AD}$ process provides new growth opportunities, including local employment for $\mathrm{AD}$ plant operation and maintenance personnel and business opportunities for the $\mathrm{AD}$ equipment manufacturer, constructors, and waste suppliers (DEFRA, 2011). Contrary to UK's vision to create a CE model using waste recycling, IEA Bioenergy (2020) reported in the UK biogas sector, only 91 municipal/commercial waste-based biogas plants out of 660, whereas landfills-based biogas plants topped with 443 plants followed by 261 agriculture-based biogas plants in the UK. IEA Bioenergy (2020) also suggested no significant growth in municipal waste-based biogas after 2015, while agriculture-based biogas continues to grow. UK government using policy instruments such as Landfill tax, double ROC, FITs, and RHI provided much need impetus for BfW plants (Zglobisz et al., 2010). However, in 2019, out of 660 AD plants, only 91 were part of the bio-waste management scheme, and 163 plants were based on sewage sludge treatment (IEA Bioenergy, 2020). It is observed that around $40 \%$ of biogas plants in the UK aim to support the recycling and resource efficiency of bio-waste/ sewage sludge. Peake and Brandmayr (2019) highlighted, in reality, waste management has a low circularity level, and the UK is off track to reach a $50 \%$ household recycling target in 2020 . The energy recovery from the waste stream using the incineration process does not fit into a $\mathrm{CE}$ model; the burning of resources destroys valuable materials and impacts resource efficiency. The lack of essential waste recycling infrastructure in the UK can be attributed to the lower circularity of material (DEFRA, 2018). We also observed that energy crops still have a significant share in UK's biogas generation in spite of the UK government has implemented feedstock sustainability criteria with (1) no more than $50 \%$ of feedstock from energy crops, (2) crops should not come from a land with a high biodiversity level (IEA Bioenergy, 2020). The UK's sustainability criteria regulation reflects a commitment towards declining energy crop use and increasing waste feedstocks in the future. However, in the present situation, the biogas producing AD plants mostly remain agriculture based having feedstocks from energy crops.

\subsection{Challenges in BfW as CE Model}

The biogas schemes have been in prime focus for several sectors like climate, energy, transport, and waste management; consequently, the biogas development can be impacted by conflicting objectives in cross-sectoral policies. Zglobisz et al. (2010) suggested that strategic and policy-related issues as barriers to biogas sector development and identified administrative, financing, and market development are the main strategic issues. Member states of the EU recognize that policy coherence is crucial to the effective development of BfW as $\mathrm{CE}$ (Kampman et al., 2017). From the CE perspective, waste management is a complex field that goes beyond waste collection and treatment; it also involves multiple government regulations and policy instruments to improve the environment, human health, and resource efficiency (Malinauskaite et al., 2017). Policy support and regulations related to waste management varies across EU countries. Within the UK, different waste management systems are applied in different regions. DEFRA (Department for Environment, Food and Rural Affairs) has jurisdiction on waste and recycling policy in England. At the same time, the agency deals closely with the devolved administrations in Walse, Scotland, and Northern Ireland (Malinauskaite et al., 2017). Van Ewijk (2018) argued CE model should be viewed as a niche market that should be created and protected by strategic long-term policy support. Therefore, it can be argued that policy uncertainty in waste recycling fails to attract new investments and remains a non-viable business case for entrepreneurs. EU member states recognize the lack of investments in waste recycling infrastructure is due to policy uncertainty and advocate stable and cohesive policy support for development and investments (Kampman et al., 2017). Like other EU states, there is a lack of investments in the UK's recycling infrastructure, which is essential for supporting the CE model. Most investments in UK's waste infrastructure are focused on residual waste treatments using incinerators without much support to a circular economy; organizations offering resource recycling solutions using disruptive design and innovative business models do not receive funding support (Peake \& Brandmayr, 2019). In the UK, withdrawal of FITs and reduction in RHI support have adversely impacted the new investments in Biogas based AD plants; due to non-viable 
business case; many plant developers are opting out even after receiving an approval (IEA Bioenergy, 2020).

To maximize social-economic values, the CE model should be viewed as a regional opportunity. Regional actors, such as local councils and municipalities, can be involved in local biogas resource planning. Local authorities and municipalities are better positioned to assess the potential of BfW biogas sources and opportunities; they can contribute to the $\mathrm{CE}$ model by increasing the use of locally produced gas and recycling the waste streams such as bio-wastes (Kampman et al., 2017). The current techno-market fix of the UK's centralized energy regime assumes the biogas sector can grow with market-driven policy instruments. In contrast to this, Levidow and Ramon (2020) advocated the eco-localizations concept localizes resource flows, output uses, and new institutional responsibility by involving civil society groups. Van Ewijk (2018) argued that the CE model's success depends on coordination between different actors, domains, and levels having a shared goal and suggested common stakeholder platforms to support constructive collaboration. Considering BfW based CE model is still a novice, these common platforms can be used to create shared knowledge involving potential stakeholders, including investors, producers, and consumers (Kampman et al., 2017). EU-funded ISABEL project conceptualized biogas communities to support the local CE model; such local communities, through social innovations, can create shared knowledge and collaborative partnership between stakeholders to create values by effective recycling of wastes (ISABEL, 2018). In the UK's centralized energy system, biomass is considered an input-substitute for fossil fuels. In contrast to this, civil society alliances from the eco-localization perspective can improve recycling resources and carbon sequestration (Levidow \& Ramon, 2020). However, due to prejudice and perceived risk in the business, community groups lack the impetus to participate in the BfW schemes, which could be a barrier in the UK's BfW sector growth (ISABEL, 2018).

Waste delivery and recycling rates are important parameters in the success of the CE model. The waste delivery system includes composition, quality, and caloric value that can influence the BfW efficiency. The waste composition, a critical factor in the waste delivery system, depends on socioeconomic factors and geographic locations. Within a country, waste stream collection systems and recycling rates vary between rural and urban areas. In the UK, waste management systems vary between England and devolved member states Scotland and Wales. In devolved governments, Wales reached the national target of waste recycling in 2012 with a $52.1 \%$ waste recycling rate against the UK's household waste recycling rate of $44.3 \%$ in 2015 (Malinauskaite et al., 2017). The waste collection infrastructure also varies significantly within the member states of the UK. In 2016-17, 97\% population in Wales had access to household food waste collection, $84 \%$ in Northern Ireland, $80 \%$ in Scotland, and lowest $40 \%$ in England; lower collection in England can be attributed to budgetary constraints and lack of clarity on household waste collection policy (Banks, Heaven, Zhang, \& Baier, 2018). UK government introduced landfill gate fees payable to waste management companies to increase food waste collection and improve the waste stream delivery system (Zglobisz et al., 2010). Economic drivers in the food waste collection and recycling system are essential for overall BfW viability (Banks et al., 2018). The gate fee for AD-based Biogas plants for 2018 in the UK reported an average of $£ 27 /$ tonne to zero or negative gate fees; this continued decline since 2015; England had lower gate fees compared to Wales and Scotland (WRAP, 2019). The gate fees in zero or negative territory show that waste management companies are either willing to pay or make no profit from the waste collection; this reflects the disruption of the waste collection system with higher demand and supply shortage of bio-wastes.

Project financing is a challenge in the BfW scheme. In the UK's market-driven financing arrangements, banks look for a robust business case to ensure a guaranteed return on investment (DEFRA, 2014). Actors involved in BfW based CE model expect to make a profit with a secured return on investment; therefore, a clear business model is essential to ensure long-term profit and strategies for efficient use of byproducts (ISABEL, 2018). Developing a profitable BfW business model in the first place without having a secured source of project financing is a major challenge for smaller organizations (DEFRA, 2014). Therefore, BfW operators should explore hybrid and shared ownership business models with private developers. Another problem is the unplanned development of waste to energy facilities resulting in gate fee decline for waste collection in England. The decline in gate fee reflects an unplanned increase in waste to energy plants for available feedstock, also disrupts a revenue stream receivable to BfW business. A lack of food waste system as feedstock in the UK is driving gate fees down to a level where the business model of BfW based AD operators becomes economically unsustainable (WRAP, 2019).

\subsection{Need for a Decentralized BfW System}

The CE model of the BfW scheme can be useful when it is integrated with the local community. Kirchherr et al. (2017) suggested a current scholarly discussion on the CE model has a narrow focus on community, including consumers and different business ecosystem actors. Having recognized the high cost and feedstock complexity as a significant barrier in biogas schemes, focusing on local farming communities, Wang (2014) proposed decentralized BfW, which will improve local waste recycling efficiency and increase the use of digestate as green 
fertilizer. The biogas communities involve actors such as citizens, social entrepreneurs, public authorities, and community organizations. These entities are referred to as decentralized biogas energy systems and create socialeconomic values using the local low-carbon economy (ISABEL,2018). The idea of a decentralized and locally embedded BfW scheme can increase the CE model's success rate, but, in the UK's top-down policy regime, such an idea remains ineffective unless supported by intermediary organizations and local actors. A collaboration working between local farmers, community groups, designers, and regulators can be proposed for the decentralized BfW scheme with aim to create socio-economic benefits in the rural regions, and improve waste recycling (Wang, 2014). In the UK's community energy sector, predominantly focused on solar and wind energy, intermediary organizations, play an active role in fill-in any policy gaps (Seyfang et al., 2014). Non-state actors such as social groups, civil bodies, and intermediary organizations collaborate and exchange knowledge to narrow the gaps in the UK government's top-down policy approach (Markantoni, 2016). In contrast to the UK, local municipalities in Italy use the decentralized BfW scheme structure, thereby improving the recycling rate at the city level and supporting the local low-carbon economy (Cucchiella et al., 2019).

\section{Discussion}

This review paper aims to understand the state of the BfW scheme in the UK using a lense of the CE model. I also identified challenges and barriers currently faced in the BfW scheme in the UK. Within the UK, it is observed that member states use diverse strategies to support the CE model, devolved states Wales and Scotland have more efficient waste resource collection and recycle strategies in comparison with England. Access to project finance has been an essential factor in developing a viable business case in the BfW scheme. In contrast to England, it is observed that devolved states through local interventions support project funding and innovation (Pitcairn, Warmington, Gandy, Deswarte \& Bell, 2017). The food waste collection in England is inconsistent. Only some local authorities operate food waste collection and recycling schemes; the UK government plans to propose legislation for mandatory separate food waste collections by 2023 (DEFRA, 2018). To overcome inconsistencies and contradictions at the regional level, the UK government should involve local authorities and city councils in the national waste management strategy, which will enable policymakers to develop actionable plans. Resourcebased local waste management plans allow local authorities a vital opportunity to engage local communities in the waste recycling process and take part in the CE model (DEFRA, 2014). In the following sections, we discuss areas that need immediate attention to usher BfW scheme potential in supporting the CE model.

\subsection{Localized BfW Schemes with a Closed System Approach}

To effectively support the CE model using the BfW scheme, it is imperative to define a system boundary. Material in-flows and outflows are identified and accounted for mass balance. In the UK, waste collection, processing, and final product distribution occur at multiple locations and involve multiple agencies. The EU Directive (2008/98/EC) on the proximity principle recommends that all the waste material be managed close to its source and local authorities should have required infrastructure. Contrary to this, the UK is more flexible in waste management, and waste generated in one city can be treated in another city having the available capacity (DEFRA, 2014). It can be argued that this operational flexibility in waste treatment location can make (1) waste infrastructure development at the city council level non-mandatory, and (2) local authorities deprived of resource efficiency benefits in the CE model based on the BfW scheme. In contrast to the UK, other European countries like Italy and Sweden plan decentralized and localized BfW scheme. In Italy, local municipalities at the city level recycle their own waste material to generate biogas, thereby, support a local CE model by closing the loop to improve resource efficiency and utilize produced biogas for energy and digestate as fertilizer (Cucchiella et al., 2019). As per the Swedish national biogas strategy, the Energigas Sweden (2018) reported 1) biogas plants should be located close to waste collection points to increase commercialization of the BfW scheme, 2) local municipalities should take overall responsibility for the BfW scheme. Within the UK, devolved state Scotland sees potential in local on-site AD to process residual food wastes. CE strategy for the Scottish government (2016) recognizes the potential for regional bio-energy hubs from biological wastes and aims to provide supports to overcome any barriers to the use of bio-waste.

Community-based BfW plants in rural areas can be a perfect case of a decentralized waste resource regeneration scheme to support a stand-alone CE model. By involving in the grassroots activities, biogas communities support the CE model, generate low-cost biogas, renewable energy, and heat; the digestate from AD plants can also be used as a fertilizer (ISABEL, 2018). In general, biogas communities, through waste management, create socialeconomic benefits for local communities. There are several biogas communities in Germany's rural areas operated in shared ownership involving local consumers, farmers, civil societies, and local municipalities. Obereschach, a borough in the district capital Villingen-Schwenningen (VS) Germany, having three biogas communities since 2004. The community members are willing to broader their operation through more citizen participation that is 
resource-efficient, environment-friendly, economically feasible, and create high benefits for the local community (ISABEL, 2016). In contrast to Germany, biogas communities are rare in the UK. As part of the ISABEL project, His Church, a charitable organization, proposed setting up a biogas community in Lincolnshire UK to process waste streams. Local authorities supported the proposal; once operational, this would be the first biogas community in the UK, which can be replicated in the new regions (ISABEL, 2018). EU-funded ISABEL Project reviewed the biogas landscape of Yorkshire and the Humber in the UK. The project team suggested community projects could seed the regional growth in the biogas sector; the project using a closed-looped economic model can create a new value chain to benefit local community groups, local food producers, and businesses (ISABEL, 2017). In the early 1990 s, the UK government and farmers' unions were visioned to set up 1000 on-farm AD plants by 2020 . NGOs and environmentalists supported this vision as waste treatment at the source effectively minimized the climate impact (Levidow \& Ramon; 2020). The localized waste management using a smaller on-farm AD process could result in higher waste recycling and resource efficiency. However, the gradual withdrawal of FIT support and the RHI reduction since 2015 has made onsite small-scale AD deployment non-viable (Levidow \& Ramon; 2020). Political changes led to policy uncertainty and incentive reversal attributed to the lack of community-based biogas projects in the UK. At the initial stage, the UK's AD strategy was based on community engagement and localism; in 2014, the UK government proposed a community energy strategy to increase decentralized and distributed community energy projects (DEFRA, 2015). However, in 2016 political changes led by neoliberal ideas supported market-driven policies that resulted in the gradual withdrawal of government incentives and subsidies to the community energy sector.

In the analysis, it is evident that localized BfW facilities improve the resource efficiency of the waste stream, also increases social-economic benefits for local communities who are part of the CE model. The community involvement in renewable energy projects is not a new concept in the UK; there are many community projects across the UK. However, these are limited to solar and wind energy generation. It is recommended that the UK government, in their CE strategy, should adopt a decentralized approach to involve local actors, municipalities, and intermediaries. This approach will help the UK increase the diffusion of community biogas projects to usher $\mathrm{BfW}$ potential for supporting the CE model.

\subsection{BfW Circular Business Model and Ecosystem}

The feedstocks and byproducts must be given marketable values to develop the BfW scheme as a viable business case. Due to quality, variability, and seasonality of feedstocks and byproducts, AD operators must collaborate with waste suppliers, digestate customers, farmers, and local residents; the transformation of low-valued bio-wastes into marketable end-products requires specific value creation strategies using a circular business model (Donner, Gohier, \& de Vries, 2020). The concept of the circular business model is new and evolving. According to Reim, Parida, and Sjödin (2019), in a circular business model, the focal organization, together with partners, uses innovative strategy to create, capture, and deliver value to improve resource efficiency by increasing waste recycling rate, thereby realizes environmental, social, and economic benefit. The circular business model creates values from bio-waste and byproducts via cascading or closing loops (Donner et al., 2020). Lack of long-term visibility on revenue streams is the main barrier to economic feasibility in a circular business model (Reim et al., 2019). The UK government, through the gate fees policy, provided a commercial value to waste feedstock. The gate fee is seen as a revenue stream to waste recycling companies; however, the gate fee for AD-based Biogas plants for 2018 in the UK reported an average of $£ 27 /$ tonne, and this continues to decline since 2015 (WRAP, 2019). Another barrier in a circular business model is the lack of efficient market channels to develop a circularity of materials (Reim et al., 2019). In spite of the growing recognition of AD digestate as bio-fertilizer, the market is immature and, also, the application of digestate in non-agriculture purposes is not yet defined (DEFRA, 2015). Further to a lack of market channels, $\mathrm{AD}$ operators using a complex procedure must get digestate certified under the bio-fertilizer certification scheme to gain access to the UK market. It is evident that under the present policy regime, the BfW scheme in the UK remains under pressure and lacks long-term viability. Therefore, policymakers must reconfigure their strategies to improve the business case for BfW schemes to commercialize the products and attract investors to get involved in the project (Malinauskaite et al., 2017).

In contrast to the linear model, the $\mathrm{CE}$ model requires diverse values, knowledge, and skills to be integrated into a closed-looped system. The business ecosystem concept is becoming relevant in circular business models; actors as part of the business ecosystem should involve and interconnect their activities to foster a collaboration (SuarezEiroa et al., 2019). A circular business model could lead to ambiguity in role and responsibility in the value creation process; a business ecosystem allows different actors to know their exact roles and responsibilities (Reim et al., 2019). A CE model should be viewed as a complex system where actors of the business ecosystem are interconnected (Ellen McArthur foundation, 2015). Therefore, the BfW scheme-based CE model requires a business 
model transformation, redefining the value proposition, including value creation, delivery, and the capture process (Donner et al., 2020; Reim et al., 2019). Using devolved power, Scotland has developed a regional strategy to support the CE model from waste recycling within the UK. The Scottish Government (2016), to create new opportunities in the circular economy, has set up biotechnology innovation centers, map bioresources into the value chain, develop local business hubs, and fund innovation activities. Knowledge of waste resource, composition, and availability of feedstocks is essential in creating a value chain system. Zero Waste Scotland developed an innovative tool that maps waste resource availability, price, and freight costs of feedstocks around Scotland; this tool helps stakeholders identify feedstock availability opportunities, including transportation costs (Attard et al., 2020). In Scotland, organizations like Zero Waste Scotland provide a platform to bringing together bio-waste generators, potential end-users, technology providers, academia, policymakers, and investors to develop value chain systems in biogas-based economy (Pitcairn et al., 2017). Among major biogas producing nations, Italy implemented a national framework in 1997 to develop bio-waste as a value chain. It made waste collection at the source mandatory that helped Italy emerge as a world leader in bio-waste recycling. Between 1997 and 2017, the amount of separate organic waste collection increased by a factor 8 , the amount of bio-waste collected separately in Italy rose about 10\% annually from the year 2000 to 2015 (Italian Composting and Biogas Association, 2017). The Italian Composting and Biogas Association recognizes the importance of the business ecosystem and provides a platform for collaboration between bio-waste producers, local authorities, machinery \& equipment constructors, research bodies, and innovators (Italian Composting and Biogas Association, 2017).

This analysis observed that revenue stream volatility, complex procedures, and lack of market channels are significant barriers in supporting circular business models in the UK. Additionally, the FIT scheme's withdrawal and reduction in RHI incentive have compounded BfW operators' problems. Scotland uses devolved rights within the UK to set up local business hubs to support circular economy opportunities and use innovative tools to map bio-waste streams. The decline in the gate fees for bio-waste in the UK indicates a bio-waste stream not given a value chain consideration. In contrast to this, Italy using a national policy, improved bio-waste stream consistency that is growing annually. It is recommended that the UK government, in their CE strategy, should consider biowaste and digestate as value streams in BfW schemes and identify clear roles and responsibilities of different actors of the business ecosystem who influence the value stream.

\subsection{Waste Recycling Infrastructure}

Adequate waste collection and recycling infrastructure is an essential part of the CE model. There is a significant regional and local difference within the UK regarding waste collection and recycling infrastructure; England has the lowest household waste collection of around $45 \%$ compared to other devolved states Scotland and Wales (Banks et al., 2018; Purnell, 2019). To increase waste collection, the UK government introduced gate-fee as an incentive to waste management operators; however, continuous decline in gate fees shows a lower supply of waste (DEFRA, 2014; WRAP, 2019). Local authorities, responsible for solid waste collection, use a competitive bidding process to hire private contractors who construct and operate waste treatment infrastructure; also, due to budgetary constraints and fiscal austerity, the waste collection gets lower priority in England (Banks et al., 2018; Purnell, 2019). In contrast to this, devolved administrations implementing clear policies for separate household food waste collections (Banks et al., 2018). Scotland amended the Waste (Scotland) Regulations 2012 to improve the food waste collection system aligned with the Scottish Government's Zero Waste Plan. Under these amendments, any person who generates, collects and treats food waste has a legal duty to ensure that the waste is managed to promote high-quality recycling (SEPA, 2016). Understandably, Scotland's emphasis on separate collection and recycling of food waste improves the feedstock supply chain for AD based BfW facilities. The Italian national legislation set a 65\% Source Separation Level (SSL) target for municipalities that resulted in improved bio-waste and food-waste collection from residential sources (Italian Composting and Biogas Association, 2017). The source-separated food waste is readily digestible in an $\mathrm{AD}$ plant without any pre-treatment, source-separated food waste fed $\mathrm{AD}$ plant has greater than $85 \%$ recycle rates (Banks et al., 2018). Lack of investments in recycling infrastructure evident in the UK, especially in England. According to Peake and Brandmayr (2019), there are limited signs of new policy induction to increase investments in the recycling infrastructure required to meet $\mathrm{CE}$ aims. The waste treatment infrastructure for energy from waste is typically centered around incinerators without much focus on recycling waste material. UK's national infrastructure plan in 2016 shows ten energy from the waste project; only two projects are based on waste recycling, while the other eight projects are incinerator-based (Purnell, 2019). Due to a lack of recycling infrastructure, valuable resources go out of the economy due to the incineration process. The UK's waste infrastructure delivery program tracks information related to incinerators, EfW plants, and landfills; however, there is no comprehensive plan for waste recycling (Peake \& Brandmayr 2019). A lack of tracking and data availability on existing recycling facilities compounds to difficulties in planning for the CE model's future 
based on resource efficiency and waste strategy. Arguably due to the lack of recycling infrastructure, many UK waste resources are exported to EU countries for energy from waste facilities (Purnell, 2019).

The above analysis shows that the waste to energy scheme is not aligned with the UK's CE strategy. The energy recovery schemes are mostly centered around the incineration process without focusing on the recycling of biowaste. As per the waste management hierarchy, the UK's waste management policy should prioritize bio-waste recycling over the incineration process. However, in practice, bio-waste recycling infrastructure gets lower preference in the national funding plan. Especially, bio-waste collection in England is less efficient compared to devolved member states Scotland and Wales. It is recommended that the UK government, in their CE strategy, create a policy cohesiveness across multiple departments to increase investments in recycling infrastructure to unleash BfW potential for the CE model.

\section{Conclusion}

This paper aimed to analyze the state of the BfW scheme in the UK through the lens of circular economy and discern areas that need attention to usher BfW potential in supporting a circular economy. The absence of crosssectoral policy coherence is a significant barrier in the development of the BfW scheme. During the analysis, I observed that the UK's BfW scheme is at the novice stage and far from contributing to a circular economy. Especially in England, the lack of a closed-loop approach in waste collection and treatment was evident. Waste collected from one city is permitted by local authorities to be treated at a different location; in the current practice, it is difficult to keep an account of material balance and prevent leakage to externalities. In England, the bio-waste feedstock is not given a value chain consideration, and currently, there is no provision for separate bio-waste collection. Also, the market for AD by-products is immature and still developing. In the analysis, the scarcity of investments in recycling infrastructure was noticeable. Having identified the key areas for improvement, I recommend in-depth studies in the areas of waste collection efficiency and recycling infrastructure investments.

To develop the CE model utilizing BfW potential, the UK government should make a strategic move from topdown policy support to create an engaging business environment to support circular business models. This paper makes three recommendations to usher BfW recycle potential to support the localized circular economy. First, it recommends that the UK government, in their CE strategy, should adopt a decentralized approach to involve local actors, municipalities, and intermediaries in BfW scheme development. Second, policymakers in the UK should consider bio-waste and digestate as value streams and identify clear roles and responsibilities of different BfW business ecosystems actors. Third, create a policy cohesiveness across multiple departments to increase recycling infrastructure investments to unleash BfW recycling potential.

\section{References}

Adams, P. W. R., Mezzullo, W. G., \& McManus, M. C. (2015). Biomass sustainability criteria: Greenhouse gas accounting issues for biogas and biomethane facilities. Energy Policy, 87, 95-109. https://doi.org/10.1016/j.enpol.2015.08.031

Attard, J., McMahon, H., Doody, P., Belfrage, J., Clark, C., Anda Ugarte, J., ... \& Gaffey, J. (2020). Mapping and Analysis of Biomass Supply Chains in Andalusia and the Republic of Ireland. Sustainability, 12(11), 4595. https://doi.org/10.3390/su12114595

Banks, C. J., Heaven, S., Zhang, Y., \& Baier, U. (2018). Food waste digestion: Anaerobic Digestion of Food Waste for a Circular Economy. IEA Bioenergy Task 37. Retrieved from https://www.ieabioenergy.com/publications/food-waste-digestion-anaerobic-digestion-of-food-waste-for-acircular-economy/

Benato, A., \& Macor, A. (2019). Italian biogas plants: Trend, subsidies, cost, biogas composition and engine emissions. Energies, 12(6), 979. https://doi.org/10.3390/en12060979

Capodaglio, A. G., Callegari, A., \& Lopez, M. V. (2016). European framework for the diffusion of biogas uses: Emerging technologies, acceptance, incentive strategies, and institutional-regulatory support. Sustainability, 8(4), 298. https://doi.org/10.3390/su8040298

Cucchiella, F., D’Adamo, I., \& Gastaldi, M. (2019). Sustainable Italian cities: The added value of biomethane from organic waste. Applied Sciences, 9(11), 2221. https://doi.org/10.3390/app9112221

DEFRA. (2011). Anaerobic digestion strategy and action plan. Retrieved from https://assets.publishing.service.gov.uk/government/uploads/system/uploads/attachment_data/file/69400/an aerobic-digestion-strat-action-plan.pdf

DEFRA. (2014). Energy from waste: A guide to the debate. Retrieved from 
https://assets.publishing.service.gov.uk/government/uploads/system/uploads/attachment_data/file/284612/p b14130-energy-waste-201402.pdf

DEFRA. (2015). Anaerobic digestion strategy and action plan annual report 2014. Retrieved from https://assets.publishing.service.gov.uk/government/uploads/system/uploads/attachment_data/file/406928/p b14019-anaerobic-digestion-annual-report-2013-14.pdf

DEFRA. (2018). Our waste, our resources: A strategy for England. Retrieved from https://assets.publishing.service.gov.uk/government/uploads/system/uploads/attachment_data/file/765914/re sources-waste-strategy-dec-2018.pdf

DEFRA. (2019). Crops grown for bioenergy in the UK: 2018. Retrieved from https://assets.publishing.service.gov.uk/government/uploads/system/uploads/attachment_data/file/856695/n onfood-statsnotice2018-08jan20.pdf

Department of Transport. (2019). Renewable Transport Fuel Obligation Guidance Part Two Carbon and Sustainability. Retrieved from https://assets.publishing.service.gov.uk/government/uploads/system/uploads/attachment_data/file/861014/rt fo-guidance-part-2-carbon-and-sustainability-guidance-year-2020.pdf

Donner, M., Gohier, R., \& de Vries, H. (2020). A new circular business model typology for creating value from agro-waste. Science of the Total Environment, 716, 137065. https://doi.org/10.1016/j.scitotenv.2020.137065

Ellen MacArthur Foundation. (2015). Towards a circular economy: Business rationale for an accelerated transition. Retrieved from https:/www.ellenmacarthurfoundation.org/assets/downloads/TCE_EllenMacArthur-Foundation 9-Dec-2015.pdf

Energigas Sweden. (2018). National biogas strategy 2.0. Retrieved from https://www.energigas.se/library/2303/national-biogas-strategy-2_0.pdf

European Biogas Association. (2019). EBA Statistical Report 2018. Retrieved from https://www.europeanbiogas.eu/eba-statistical-report-2018/

Fagerström, A., Al Seadi, T., Rasi, S., \& Briseid, T. (2018). The role of anaerobic digestion and biogas in the circular economy. IEA Bioenergy. Retrieved from https://www.ieabioenergy.com/wpcontent/uploads/2018/08/anaerobic-digestion_web_END.pdf

IEA Bioenergy. (2017). IEA Bioenergy Task 37. UK country report 2017. Paris: IEA Bioenergy. Retrieved from http://task37.ieabioenergy.com/country-reports.html?file=files/datenredaktion/download/publications/countryreports/2017/IEA\%20UK\%20Country\%20Report\%20Sept\%202017.pdf

IEA Bioenergy. (2020). IEA Bioenergy Task 37. Country report summaries 2019. Paris: IEA Bioenergy. Retrieved from https://www.ieabioenergy.com/wp-content/uploads/2020/03/IEA-Task-37-Country-Report-Summaries2019-1.pdf

ISABEL. (2016). Biogas social innovation platforms and communities. Retrieved from https://isabelproject.eu/item/report-on-the-biogas-social-innovation-platforms-and-communities/

ISABEL. (2017). ISABEL findings in the UK region of Yorkshire and the Humber. Retrieved from https://isabelproject.eu/wp-content/uploads/ISABEL_UK_Report_Final-1.pdf

ISABEL. (2018). Recommendations best practice and replication guide. Retrieved from https://isabelproject.eu/wp-content/uploads/ISABEL_Recommendations-best-practice-and-replication-guide.pdf

Italian Composting and Biogas Association. (2017). Annual report on biowaste recycling. Retrieved from https:/www.compost.it/wp-content/uploads/2019/08/Rapporto-CIC-2017-Eng-v-2.6-web-version.pdf

Kampman, B., Leguijt, C., Scholten, T., Tallat-Kelpsaite, J., Brückmann, R., Maroulis, G., ... \& Elbersen, B. (2017). Optimal use of biogas from waste streams: an assessment of the potential of biogas from digestion in the EU beyond 2020.

Kirchherr, J., Reike, D., \& Hekkert, M. (2017). Conceptualizing the circular economy: An analysis of 114 definitions. Resources, conservation and recycling, 127, 221-232. https://doi.org/10.1016/j.resconrec.2017.09.005

Lauer, M., Hansen, J. K., Lamers, P., \& Thrän, D. (2018). Making money from waste: The economic viability of producing biogas and biomethane in the Idaho dairy industry. Applied Energy, 222, 621-636. 
https://doi.org/10.1016/j.apenergy.2018.04.026

Levidow, L., \& Raman, S. (2020). Sociotechnical imaginaries of low-carbon waste-energy futures: UK technomarket fixes displacing public accountability. Social Studies of Science, 50(4), 609-641. https://doi.org/10.1177/0306312720905084

Lindkvist, E., Karlsson, M., \& Ivner, J. (2019). Systems analysis of biogas production-Part I research design. Energies, 12(5), 926. https://doi.org/10.3390/en12050926

Malinauskaite, J., Jouhara, H., Czajczyńska, D., Stanchev, P., Katsou, E., Rostkowski, P., ... \& Anguilano, L. (2017). Municipal solid waste management and waste-to-energy in the context of a circular economy and energy recycling in Europe. Energy, 141, 2013-2044. https://doi.org/10.1016/j.energy.2017.11.128

Markantoni, M. (2016). Low carbon governance: mobilizing community energy through top - down support? Environmental Policy and Governance, 26, 155-169. https://doi.org/10.1002/eet.1722

Menzies, B., Mary Dimambro, M., \& Aspray, T. (2019, March). Scottish anaerobic digestion and biogas sector survey 2017. Retrieved from https://www.zerowastescotland.org.uk/sites/default/files/Scottish\%20anaerobic\%20digestion\%20and\%20bi ogas $\% 20$ sector\%20survey\%202017.pdf

Murray, A., Skene, K., \& Haynes, K. (2017). The circular economy: an interdisciplinary exploration of the concept and application in a global context. Journal of business ethics, 140(3), 369-380. https://doi.org/10.1007/s10551-015-2693-2

Peake, L., \& Brandmayr, C. (2019). Building a circular economy How infrastructure can support resource efficiency. Green Alliance London. Retrieved from https://www.greenalliance.org.uk/resources/Building_a_circular_economy.pdf

Pitcairn, J., Warmington, J., Gandy, S., Deswarte, F., \& Bell, J. (2017). Biorefining potential for Scotland: Mapping bioresource arisings across Scotland. Industrial Biotechnology, 13(6), 301-305. https://doi.org/10.1089/ind.2017.29111.jpi

Purnell, P. (2019). On a voyage of recovery: A review of the UK's resource recovery from waste infrastructure. Sustainable and Resilient Infrastructure, 4(1), 1-20. https://doi.org/10.1080/23789689.2017.1405654

Rada, E. C., Ragazzi, M., Torretta, V., Castagna, G., Adami, L., \& Cioca, L. I. (2018, May). Circular economy and waste to energy. In AIP Conference Proceedings. 1968, 030050. https://doi.org/10.1063/1.5039237

Reim, W., Parida, V., \& Sjödin, D. R. (2019). Circular business models for the bio-economy: A review and new directions for future research. Sustainability, 11(9), 2558. https://doi.org/10.3390/su11092558

Rolewicz-Kalińska, A., Lelicińska-Serafin, K., \& Manczarski, P. (2020). The Circular Economy and Organic Fraction of Municipal Solid Waste Recycling Strategies. Energies, 13(17), 4366. https://doi.org/10.3390/en13174366

Scottish Govt. (2016). Making things last: A circular economy strategy for Scotland. Retrieved from https://www.gov.scot/publications/making-things-last-circular-economy-strategy-scotland/

SEPA. (2016). Food waste management in Scotland. Retrieved from https://www.sepa.org.uk/media/219841/wstg-049-food-waste-management-in-scotland.pdf

Seyfang, G., Hielscher, S., Hargreaves, T., Martiskainen, M., \& Smith, A. (2014). A grassroots sustainable energy niche? Reflections on community energy in the UK. Environmental Innovation and Societal Transitions, 13(1), 21-44. https://doi.org/10.1016/j.eist.2014.04.004

Suárez-Eiroa, B., Fernández, E., Méndez-Martínez, G., \& Soto-Oñate, D. (2019). Operational principles of circular economy for sustainable development: Linking theory and practice. Journal of cleaner production, 214, 952961. https://doi.org/10.1016/j.jclepro.2018.12.271

Van Ewijk, S. (2018). Resource efficiency and the circular economy. Concepts, economic benefits, barriers, and policies. UCL Institute for Sustainable Resources,1-21. Retrieved from http://randd.defra.gov.uk/Document.aspx?Document=14264_Resourceefficiencyandcirculareconomy.pdf

Wang, J. (2014). Decentralized biogas technology of anaerobic digestion and farm ecosystem: Opportunities and challenges. Frontiers in Energy Research, 2, 1-12. https://doi.org/10.3389/fenrg.2014.00010

WRAP. (2015). Economic growth potential of_more circular economies. Retrieved from https://www.wrap.org.uk/content/economic-growth-potential-more-circular-economies 
WRAP. (2016). Digestate and compost use in agriculture. Retrieved from https://www.wrap.org.uk/sites/files/wrap/WRAP_Digestate_and_compost_use_in_agriculture_for_farmers_ growers_and_advisers.pdf

WRAP. (2019). Gate fees report 2019: Comparing the costs of alternative waste treatment options. Retrieved from https://wrap.org.uk/sites/files/wrap/WRAP\%20gate\%20fees\%20report\%202019.pdf

Yazan, D. M., Cafagna, D., Fraccascia, L., Mes, M., Pontrandolfo, P., \& Zijm, H. (2018). Economic sustainability of biogas production from animal manure: a regional circular economy model. Management research review, 41(5), 605-624. https://doi.org/10.1108/MRR-02-2018-0053

Zglobisz, N., Castillo-Castillo, A., Grimes, S., \& Jones, P. (2010). Influence of UK energy policy on the deployment of anaerobic digestion. Energy Policy, 38(10), 5988-5999. https://doi.org/10.1016/j.enpol.2010.05.054

\section{Copyrights}

Copyright for this article is retained by the author(s), with first publication rights granted to the journal.

This is an open-access article distributed under the terms and conditions of the Creative Commons Attribution license (http://creativecommons.org/licenses/by/4.0/). 